\title{
ELIMINATION OF DYES FROM AQUEOUS SOLUTIONS USING IRON OXIDES AND CHITOSAN AS ADSORBENTS. A COMPARATIVE STUDY
}

\author{
Silvina Pirillo*, Viviana Pedroni y Elsa Rueda \\ Departamento de Química, Universidad Nacional del Sur, CP 8000, Bahía Blanca, Argentina \\ María Luján Ferreira \\ Planta Piloto de Ingeniería Química, Universidad Nacional del Sur (UNS-CONICET), Camino La Carrindanga km 7, CC 717, \\ CP 8000, Bahía Blanca, Argentina
}

Recebido em 5/9/08; aceito em 4/12/08; publicado na web em 7/5/09

\begin{abstract}
This work investigates the adsorption of Alizarin, Eriochrome Blue Black R and Fluorescein using chitosan, goethite and magnetite as adsorbents. For Alizarin, the best adsorbent is chitosan with a Langmuir parameter of $15.8 \mathrm{mmol}$ dye/g adsorbent. For Eriochrome Blue Black R only $1.94 \mathrm{mmol}$ dye/g chitosan is adsorbed. Langmuir parameters for the Alizarin adsorption on both iron oxides display one or two orders of magnitude lower than for chitosan and two orders of magnitude lower in the case of Eriochrome Blue Black R. Fluorescein does not adsorb in appreciable amounts on chitosan and it presents the lower affinity on the iron oxides.
\end{abstract}

Keywords: dyes; iron oxides; chitosan.

\section{INTRODUCTION}

The textile effluents composition is complex since it contains diverse dyes and other products such as dispersants, acids, alkalis, salts and some heavy metals. ${ }^{1}$ In general the effluent is highly colored, with a high biological (BOD) and chemistry demands of oxygen (COD)..$^{2,3}$

Dyes are present in the textile effluent in concentrations of 10 to $50 \mathrm{mg} / \mathrm{L}$. Approximately $1.000 .000 \mathrm{~kg} /$ year of dyes are discharged in effluents by the textile industries, because approximately a $15 \%$ of the total dye used in the process is lost during the dying process. Color removal from textile effluents has been the target of great attention in the last few years, not only because of its potential toxicity, but mainly due to the potential environmental impact. ${ }^{4,5}$ Different treatments for the removal of dyes have been used such as special processes of filtration, activated mud, chemical coagulation, adsorption on activated carbon and processes of photodegradation. ${ }^{6}$ The solution to the problem depends on the use of different technological process.

One of the methods used to eliminate dyes of the effluents is the adsorption on a solid material. The most common adsorbent is the activated carbon, effective in the removal of organic components and not effective in the removal of inorganic compounds. ${ }^{7}$ Due to its high cost, the use of alternative and efficient adsorbents for the removal of dyes and metals is been increasingly studied. The bioadsorbents are biodegradable polymers present in nature. Because of their structure they allow the adsorption of different species of the dyes. There are numerous reports on adsorption of dyes using as adsorbents cellulose, chitin and chitosan. ${ }^{8}$ Chitosan has excellent properties for the adsorption of anionic dyes, principally due to the presence of protonated amino groups $\left(-\mathrm{NH}_{3}^{+}\right)$in the polymer matrix, which interact with dyes in solution by ion exchange, at an appropriate $\mathrm{pH} \cdot{ }^{9-11}$ Literature has demonstrated that the capacity of adsorption of reactive dyes in a neutral medium on chitosan is of $1000-1100 \mathrm{~g}$ per kg. ${ }^{9}$ The high content of amine groups in chitosan can also originate electrostatic attraction to anionic dyes. Since the amine groups are more easily protonated at $\mathrm{pH}$ lower than 6 , the group of Chiou recommended to control the chitosan dissolution in acid effluents by a stabilization

*e-mail: spirillo@uns.edu.ar step through cross-linking agents. ${ }^{12}$ The authors reported 3800 and $3300 \mathrm{~g}$ per $\mathrm{kg}$ as the maximum adsorption capacity, at $30^{\circ} \mathrm{C}$ and $\mathrm{pH}$ 3 , for Alizarin Violet and Blue Reactive 4, respectively.

Oxides and metal hydroxides have also been used as adsorbents in the textile industry. The adsorption of cationic and anionic dyes on hydrated zirconium oxide or iron oxides has been reported. ${ }^{13}$ These materials are common as adsorbents by their limited solubility and their amphoteric properties. However, sometimes these oxides present low surface area and this aspect is a problem to resolve. ${ }^{14}$

In a previous work we have investigated the efficiency of three iron oxides (goethite, Co-goethite and magnetite) to remove synthetic dyes (Alizarin, Eriochrome Blue Black R and Fluorescein) from aqueous solutions as a function of initial dye concentration and the contact time on adsorption process. ${ }^{15}$ The objective of this work is to compare the results the adsorption of two iron oxides with those using a biopolymer (chitosan). These dyes were chosen because of their structures, which are commonly present in dyes of the textile industry. Thermodynamics and kinetics data were analyzed and discussed with the goal of a further understanding of the dyes adsorption process.

\section{EXPERIMENTAL}

\section{Materials}

\section{Adsorbates}

Three different commercial available textile dyes were used in the study: (1) Alizarin (anthraquinone dye)-with a $\lambda_{\text {max }}(\mathrm{nm})=531$, (2) Eriochrome Blue Black R (azo dye)-with a $\lambda_{\text {max }}(\mathrm{nm})=527$, and (3) Fluorescein (triarylmethane dye) with a $\lambda_{\text {max }}(\mathrm{nm})=491$. The experiments were carried out with a background concentration of 0.05 $\mathrm{mol} / \mathrm{L} \mathrm{NaCl}$ to maintain a constant ionic strength. Chemical structures of the dyes used are shown in Scheme 1S (Supplementary Material). All reagents used in this study were of an analytical grade.

Alizarin is insoluble in water but soluble in aqueous alkaline solutions in the $\mathrm{pH}$ range 7.82-12.87. At $\mathrm{pH}$ below 5.2 most Alizarin is present in the form of yellow-colored undissociated molecules. At $\mathrm{pH}$ between 6.8 and 10.1 most Alizarin occurs as red monovalent anions. At $\mathrm{pH}$ above 12.1 Alizarin dissociates into divalent anions with a blue-violet color. ${ }^{16}$ Eriochrome Blue Black R presents two 
different $\mathrm{pK}$ values (7.4 and 13.8) at the range of $\mathrm{pH}$ studied and can be present with two or three negative charges. The $\mathrm{pK}_{\mathrm{a}}$ of the sulfonic acid is 1 . In the case of Fluorescein, the $\mathrm{pK}_{\mathrm{a}}$ of the $\mathrm{OH}$ group attached to the xanthene moiety is 6.43. At $\mathrm{pH} 9.1$ Fluorescein exists purely as dianion specie while at $\mathrm{pH} 5.4$, the dominant specie is monoanion $(85 \%)$ being dianion and neutral species only $15 \% .^{17}$

\section{Adsorbents}

Chitosan

The chitosan is a fine powder (100\% finer than 100 mesh and $70 \%$ finer than 150 mesh) with $2 \%$ of acetylation and trade or commercial name Primex TM 809. The BET surface area is $4 \mathrm{~m}^{2} / \mathrm{g}$.

\section{Goethite}

The goethite was prepared by adding aqueous $\mathrm{Fe}\left(\mathrm{NO}_{3}\right)_{3} \cdot 9 \mathrm{H}_{2} \mathrm{O}$ $(0.05 \mathrm{~mol})$ to $\mathrm{NaOH}(2.5 \mathrm{~mol} / \mathrm{L})$ to reach a $1.5 \mathrm{OH}: \mathrm{Fe}$ ratio, in a final volume of $100 \mathrm{~mL}$. The precipitate was aged at room temperature for $48 \mathrm{~h}$ and then in a vacuum oven at $65^{\circ} \mathrm{C}$ for $72 \mathrm{~h} .{ }^{18}$

\section{Magnetite}

Magnetite was prepared by adding $\mathrm{FeSO}_{4} .7 \mathrm{H}_{2} 0(250 \mathrm{~mL}, 0.53$ $\mathrm{mol} / \mathrm{L})$ with constant rate $\left(2.8 \mathrm{~cm}^{3} / \mathrm{min}\right)$ to $300 \mathrm{~mL}$ of a solution containing $0.35 \mathrm{~mol}$ of $\mathrm{NaOH}$ and $0.05 \mathrm{~mol}$ of $\mathrm{NaNO}_{3}$ under vigorous stirring. The sample was aged at room temperature for 16 days. ${ }^{19}$

All samples were washed up to raise the conductivity of double distilled water. Then, they were dried at $40{ }^{\circ} \mathrm{C}$ for $72 \mathrm{~h}$ before use. The samples were characterized by chemical analyses and $\mathrm{X}$-ray diffraction. In goethite only one phase is present; however, in magnetite the appearance of a secondary phase (goethite) with less than $3 \%$ of total weight is detected. The specific surface area of the samples was measured by the classical Brunauer-Elmet-Teller method using a multiple point adsorption nitrogen process $(\text { BET-N })_{2}$ ). The BET surface area of goethite was $69 \mathrm{~m}^{2} / \mathrm{g}$ and the BET surface area of magnetite $42 \mathrm{~m}^{2} / \mathrm{g}$.

\section{Methods}

\section{Kinetic experiments}

Iron oxides

A known quantity of adsorbent was contacted with $100 \mathrm{~mL}$ of the dye solution with predetermined initial dye concentration of $25 \mathrm{mg} / \mathrm{L}$, in a thermostatic shaker bath at room temperature for a given recorder time. The initial $\mathrm{pH}$ of the solutions was adjusted to $7.10 \pm 0.1$ by the addition of either diluted solutions of sodium hydroxide or hydrochloric acid. The concentration of adsorbent was $1 \mathrm{~g} / \mathrm{L}$ for goethite and $2 \mathrm{~g} / \mathrm{L}$ for magnetite considering that the BET surface area of magnetite was lower than the BET surface area of goethite. After a specified stirring time period, the reaction mixture was vacuum filtered.

The adsorbed amounts at different contact times were expressed as mmol of dye/g of adsorbent. They were determined by the difference between initial and final concentration measured spectrophotometrically with a Cecil UV-VIS Spectrophotometer.

\section{Chitosan}

The interaction between chitosan and Alizarin, Eriochrome Blue Black R and Fluorescein at room temperature and $\mathrm{pH} 7.10$ \pm 0.1 was studied. The dye concentration used for Alizarin was between 50 and $300 \mathrm{mg} / \mathrm{L}$, for Eriochrome Blue Black R between 2.5 and $125 \mathrm{mg} / \mathrm{L}$, and for Fluorescein between 2.5 and $125 \mathrm{mg} / \mathrm{L}$. All the solutions used were prepared in double distilled water. The relation between adsorbent/adsorbate was $0.1 \mathrm{~g}$ of chitosan/ $\mathrm{L}$ of dye solution.

\section{Equilibrium experiments}

Iron oxides

The adsorbent was added to solutions with different concentrations of dye (a range between $15-120 \mathrm{mg} / \mathrm{L}$ of initial dye concentration was used) into $250 \mathrm{~mL}$ flasks and subsequently placed on a shaker for $2 \mathrm{~h}$ at room temperature. The adsorbent concentrations were: $2 \mathrm{~g} / \mathrm{L}$ for magnetite and $1 \mathrm{~g} / \mathrm{L}$ for goethite. The contact time was chosen to assure the maximum adsorption capacity. After equilibrium, each sample was filtrated with a $0.45 \mu \mathrm{m}$ membrane filter to remove the solid particles.

\section{Chitosan}

From the results of the kinetics experiences described above the isotherm a pH 7 could be obtained.

The dye adsorbed amounts (determined spectrophotometrically by the difference between initial and final concentration) were expressed as mmol of dye/g of adsorbent.

In this study, Langmuir isotherm has been investigated to fit the adsorption data. The Langmuir equation can be written in the following form:

$q_{e}=K_{L} C_{e} / 1+a_{L} C_{e}$

where $\mathrm{q}_{\mathrm{e}}$ is solid phase sorbate concentration at equilibrium ( $\left.\mathrm{mmol} / \mathrm{g}\right)$, $\mathrm{C}_{\mathrm{e}}$ is aqueous phase sorbate concentration at equilibrium $(\mathrm{mmol} / \mathrm{L})$, $\mathrm{K}_{\mathrm{L}}$ is Langmuir isotherm constant $(\mathrm{L} / \mathrm{g}), \mathrm{a}_{\mathrm{L}}$ is Langmuir isotherm constant $(\mathrm{L} / \mathrm{mmol}), \mathrm{q}_{\max }$ the amount of adsorbate adsorbed/mass of adsorbent for complete monolayer ( $\mathrm{mmol} / \mathrm{g}$ ). Descriptions and details on this isotherm can be found elsewhere. ${ }^{20,21}$

\section{Effect of $\mathrm{pH}$ in the adsorption}

\section{Iron oxides}

The solution $\mathrm{pH}$ values ranged from 3 to 9 . A known amount of each oxide (50 mg of goethite and $100 \mathrm{mg}$ of magnetite) was added to $25 \mathrm{~mL}$ of dye solution $(75 \mathrm{mg} / \mathrm{L})$. The $\mathrm{pH}$ was adjusted by the addition of $\mathrm{HCl}$ or $\mathrm{NaOH}$ under continuous stirring at room temperature. After $2 \mathrm{~h}$ of equilibration period, aliquots were removed from the suspension and filtered. The quantity of each dye adsorbed onto iron oxides was determined spectrophotometrically and subtracted from the initial concentration to determine the adsorbed amount.

\section{Chitosan}

The dye concentration used for Alizarin ranged between 50 and $300 \mathrm{mg} / \mathrm{L}$, for Eriochrome Blue Black R between 2.5 and $125 \mathrm{mg} / \mathrm{L}$, and for Fluorescein between 2.5 and $125 \mathrm{mg} / \mathrm{L}$. All the solutions used were prepared in double distilled water. The relation between adsorbent/adsorbate was $0.1 \mathrm{~g}$ of chitosan/ $\mathrm{L}$ of dye solution.

In the case of chitosan, the adsorption of dyes at room temperature at $\mathrm{pH} 5,7$ and 9 was studied, since at $\mathrm{pH} 3$ chitosan is soluble.

\section{RESULTS AND DISCUSSION}

\section{Kinetic experiments}

Figure 1 shows the adsorption of Alizarin, Eriochrome Blue Black R and Fluorescein as function of time on goethite and magnetite for a dye concentration of $25 \mathrm{mg} / \mathrm{L}$. Figure 2 shows the adsorption of Alizarin and Eriochrome Blue Black R on chitosan as function of time and using different initial dyes concentrations. Because of Fluorescein adsorption on chitosan showed a low affinity and a wide dispersion of the data, these results are not included in Figure 2. 

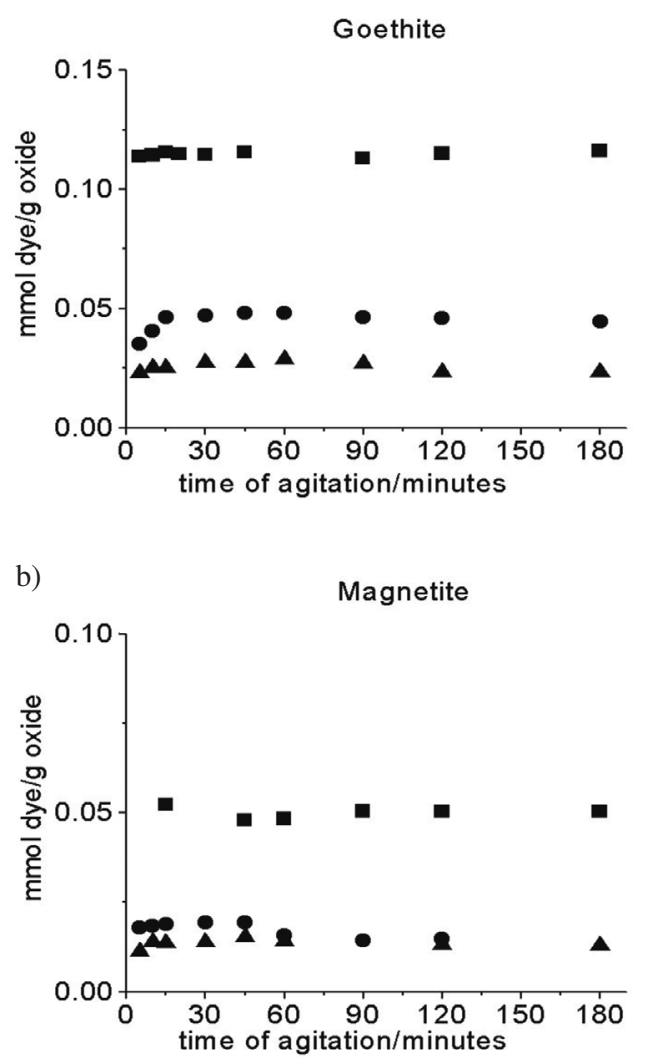

Figure 1. Kinetic adsorption of Alizarin, Eriochrome Blue Black $R$ and Fluorescein with goethite and magnetite. Dye concentration $25 \mathrm{mg} / \mathrm{L}$. (ロ) Alizarin, (•) Eriochrome Blue Black R, and (४) Fluorescein

All the dyes studied display a fast adsorption on both iron oxides. In all cases the equilibrium is reached within of the first sixty minutes. Additional studies performed at various initial dye concentrations indicated that the adsorption occurred very quickly in the same period time (results not shown). A similar behavior is observed for Alizarin and Eriochrome Blue Black R on chitosan. The adsorption occurred very quickly within the first $90 \mathrm{~min}$ and independence of the equilibrium time with the initial dye concentration is also observed. Önal ${ }^{22}$ used several kinetic models to examine the controlling mechanism of adsorption process such as chemical reaction, diffusion control and mass transfer. This author found that the dye's uptake process could be controlled by external mass transfer at earlier stages (before $5 \mathrm{~min}$ ) and by intraparticle diffusion at later stages (after $5 \mathrm{~min}$ ). Maximova and Koumanova ${ }^{23}$ for the adsorption of Basic Blue 5 (anthraquinone structure) and Basic Red 18 (diazo structure) onto the Perfil M-100 and Perfil-150 supplied by the "Bentonite" AD in Kardjale also found a rapid adsorption process.

Since the iron oxides are closely related in their behavior and surface structure, the BET surface area can be considered as a parameter useful to compare their adsorption capacity. However, because of the low BET surface area of chitosan all the amount of dyes adsorbed are depicted as mmols of dye adsorbed by gram of adsorbent.

\section{Adsorption isotherms}

Although Alizarin self-associates in aqueous solution below $\mathrm{pH}<7.82$, all isotherms in this work can be described by Langmuir equation. Aggregation may occur in solution as much as on the adsorbate surface, where each dye particle or aggregate behaves as a single molecule of the dye. ${ }^{24}$ Thus, the Langmuir equation should

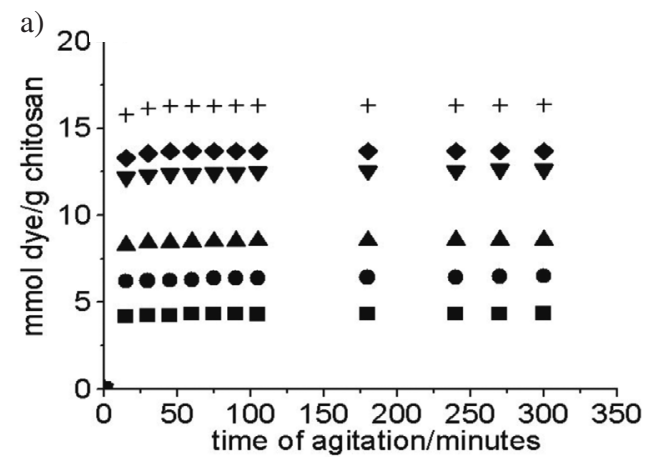

b)

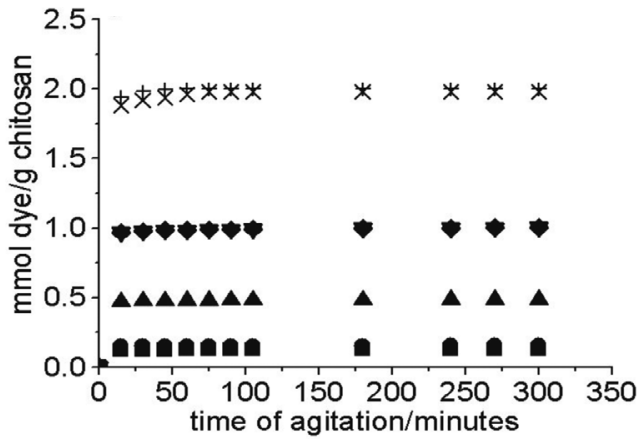

Figure 2. a) Adsorption of Alizarin on chitosan. (ロ) $50 \mathrm{mg} / \mathrm{L}$, (•) $75 \mathrm{mg} / \mathrm{L}$,

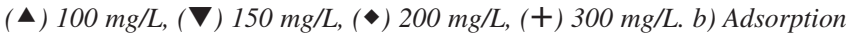

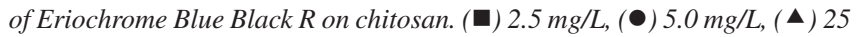
$\mathrm{mg} / \mathrm{L},(\boldsymbol{\nabla}) 50 \mathrm{mg} / \mathrm{L},(\bullet) 75 \mathrm{mg} / \mathrm{L},(+) 100 \mathrm{mg} / \mathrm{L},(\times) 125 \mathrm{mg} / \mathrm{L}$

also describe the adsorption of dimmers or oligomers, which would give rise to an adsorbed multilayer of dyes. In this way, Harris et al. ${ }^{25}$ also found that the Langmuir equation described the adsorption of dyes to kaolinite under most conditions -including dyes aggregates. The values of Langmuir parameters for the iron oxides and chitosan at $\mathrm{pH} 7$ are presented in Table 1 .

Table 1. Langmuir parameters at $\mathrm{pH} 7$ of monolayer for the best fit. $\left(\mathrm{T}=25^{\circ} \mathrm{C}\right)$
System

Alizarin-goethite

Alizarin-magnetite

Eriochrome-goethite

Eriochrome-magnetite

Fluorescein-goethite

Fluorescein-magnetite

Alizarin-chitosan

Eriochrome-chitosan
Monolayer $\mathrm{q}_{\text {max }}$ (mmol dye/g adsorbent)

$1.54 \pm 9.87 \times 10^{-2}$

$2.74 \times 10^{-1} \pm 1.12 \times 10^{-2}$

$6.63 \times 10^{-2} \pm 4.54 \times 10^{-3}$

$3.66 \times 10^{-2} \pm 6.09 \times 10^{-4}$

$0.10 \pm 9.51 \times 10^{-3}$

$1.13 \times 10^{-2} \pm 1.50 \times 10^{-4}$

$15.8 \pm 7.79 \times 10^{-1}$

$1.94 \pm 5.84 \times 10^{-2}$
These data show that chitosan is the best adsorbent for Alizarin with a Langmuir parameter of monolayer of $15.82 \mathrm{mmol}$ dye/g adsorbent. In the case of Eriochrome Blue Black R only $1.94 \mathrm{mmol}$ dye/g adsorbent was registered. Langmuir parameters for the Alizarin adsorption on both iron oxides magnetite and goethite display one or two orders of magnitude lower ( 0.274 to $1.54 \mathrm{mmol}$ dye/g adsorbent) 
and two order of magnitude lower $\left(3.6610^{-2}\right.$ to $6.6310^{-2} \mathrm{mmol}$ dye/g adsorbent) than chitosan for Eriochrome Blue Black R. On the other hand, Fluorescein was not adsorbed on chitosan in significant amounts and the adsorption data obtained at $\mathrm{pH} 7$ did not present a useful fit with the Langmuir isotherm. Comparing the Fluorescein adsorption on iron oxides it can be observed a weak interaction of this dye with magnetite. So, chitosan is by far the best adsorbent for Alizarin and Eriochrome Blue Black R whereas Fluorescein was poorly adsorbed on chitosan. On the other hand, Fluorescein is adsorbed on iron oxides in similar amounts than Alizarin and Eriochrome Blue Black R. Other authors studied modified cellulose, clays, Amberlite, chitosan, activated carbons, non-porous carbon, mesoporous and microporous carbon for the adsorption of alkylbenzenesulfonate, tannic acid, humic acid, reactive red 222, acid orange 51, acid orange 8 and methylene blue used the cited isotherm. ${ }^{21,26-29}$ The solutes above mentioned were selected because they are found in textile wastewaters. Our results with chitosan for Alizarin and Eriochrome Blue Black R are very encouraging. The iron oxides used in our work have similar adsorption abilities than the clays reported by Juang et al. ${ }^{30}$

\section{Effect of $\mathrm{pH}$}

Table 2 shows the adsorption data of the three dyes studied on goethite, magnetite at $\mathrm{pH} 3,5,7$ and 9, and chitosan at $\mathrm{pH} 5,7$ and 9.

Table 2. Effect of $\mathrm{pH}$ in the adsorption of Alizarin, Eriochrome Blue Black R and Fluorescein. Initial dye concentration $75 \mathrm{mg} / \mathrm{L}$

\begin{tabular}{lcccc}
\hline Dye & $\mathrm{pH}$ & $\begin{array}{c}\text { mmol dye } \\
\text { ads./g chitosan }\end{array}$ & $\begin{array}{c}\text { mmol dye } \\
\text { ads./g goethite ads./g magnetite }\end{array}$ \\
\hline $\begin{array}{l}\text { Eriochrome } \\
\text { Blue Black R }\end{array}$ & 3 & - & 0.11 & 0.06 \\
$\begin{array}{l}\text { Eriochrome } \\
\text { Blue Black R }\end{array}$ & 5 & 1.08 & 0.11 & 0.04 \\
$\begin{array}{l}\text { Eriochrome } \\
\text { Blue Black R }\end{array}$ & 7 & 2.00 & 0.06 & 0.03 \\
$\begin{array}{l}\text { Eriochrome } \\
\text { Blue Black R }\end{array}$ & 9 & 1.00 & 0.04 & 0.02 \\
Alizarin & 3 & - & 0.19 & 0.06 \\
Alizarin & 5 & 3.86 & 0.19 & 0.07 \\
Alizarin & 7 & 16.33 & 0.18 & 0.07 \\
Alizarin & 9 & 3.64 & 0.17 & 0.06 \\
Fluorescein & 3 & - & 0.18 & 0.07 \\
Fluorescein & 5 & $9.03 \times 10^{-4}$ & 0.10 & 0.05 \\
Fluorescein & 7 & 0.09 & 0.04 & 0.04 \\
Fluorescein & 9 & $3.01 \times 10^{-4}$ & 0.02 & 0.03 \\
\hline
\end{tabular}

To understand the different adsorption behavior obtained at the $\mathrm{pH}$ studied between the chitosan and the iron oxides is important to take account the chitosan structure. The chitosan polymeric chain is usually described as a copolymeric chemical structure composed by D-glucosamine residues (D) and $\mathrm{N}$-acetylated residues (A). The relative quantity of A monomers residues is the degree of acetylation (DA). Many authors believe that the presence of $\mathrm{NH}_{2}$ groups (and $\mathrm{NH}_{3}^{+}$) is the key to understand the adsorption capabilities of the biopolymer. The three parameters controlling the chitosan behavior in aqueous media are: degree of deacetylation, solubility and molecular mobility. Considering the fully deacetylated chitosan, one $\mathrm{NH}_{3}^{+}$group by each $0.514 \mathrm{~nm}$ in chitosan can be expected. The most important parameters to take into account are: chain accessibility, mobility and charge density. Chitosan exhibits an $-\mathrm{NH}_{3}{ }^{+}$fraction of 0.9 at $\mathrm{pH} 4$ and 0.5 at $\mathrm{pH}$ 6. So, at $\mathrm{pH} 6$ the electrostatic interaction between the chitosan and the anionic dye would be weakened. ${ }^{30}$ The adsorption capacity depends on the available amino groups present in the chitosan structure. ${ }^{31,32}$ Although, Wu et al. ${ }^{9}$ considered that intraparticle diffusion plays an important role in the sorption mechanism, the uptake of dyes on chitosan may also proceed through ion-exchange mechanisms. The major adsorption site of chitosan is a primary amine group which is easily protonated to form $-\mathrm{NH}_{3}{ }^{+}$in acidic solutions. The strong electrostatic interaction between the $-\mathrm{NH}_{3}^{+}$groups and dye anions can be used to explain the sorption mechanism. ${ }^{33}$ The difference in the degree of adsorption may also be attributed to the chemical structure of each dye..$^{34}$

On chitosan, adsorption of dye molecules is proposed to take place in two steps: first the dye is transferred from the solution to the surface; the last stage is related to the diffusion of the dye within the pores of the material, binding the pores and capillary spaces. ${ }^{35}$ These processes seem to be very fast with the dyes here studied. The $\mathrm{pK}_{\mathrm{a}}$ for chitosan is near to 6.3 , so the anion dye sorption through exchange of ions is favored at low $\mathrm{pH}$ values. However, chitosan forms gels below 5.5. The effluents acidity could severely limit the use of chitosan as an adsorbent in removing dyes, because of potential gel formation/ dissolution of the adsorbent at acidic $\mathrm{pH}$ values. At $\mathrm{pH}$ above 7, the excessive hydroxyl ions concentration may compete with the dye anions for the adsorption active sites and hence a slow reduction in dye uptake can be observed. Contrary to the expected the dye uptake at $\mathrm{pH} 5$ is smaller than at $\mathrm{pH}$ 7. For Alizarin this behavior can be explained taken into account the intermolecular reactions on chitosan and probably the presence of not ionized Alizarin at this $\mathrm{pH}$ (because one of the $\mathrm{pK}_{\mathrm{a}}$ is 5.25). In the case of Eriochrome Blue Black R the smaller amount adsorbed at this $\mathrm{pH}$ compared with the others dyes can be attributed to the interaction of the surface species with the $\mathrm{SO}_{3}{ }^{-}$group and the probable dimerization of the dye.

Table 2 shows that at pH 5, 7 and 9 chitosan is the best adsorbent for Alizarin and Eriochrome Blue Black R. However, chitosan is the best adsorbent for Fluorescein only at $\mathrm{pH}$ 7. It seems that in the case of chitosan, electrostatic forces are very strong. The amino and hydroxyl groups can function together to stabilize negative charged species. However, the decreased order in the amount of dye adsorbed on chitosan is: Alizarin > Eriochrome Blue Black R > Fluorescein. Contrary to Alizarin the kind of structure of Eriochrome Blue Black $\mathrm{R}$ makes difficult the intraparticle diffusion in chitosan. ${ }^{35}$

A low affinity of these dyes for the iron oxides is observed. The amount of Alizarin adsorbed on goethite decreases slightly in the $\mathrm{pH}$ range studied with the increase of the $\mathrm{pH}(0.19$ to $0.17 \mathrm{mmol}$ dye/g adsorbent). Higher decrease with the increase of the $\mathrm{pH}$ was observed for Eriochrome Blue Black R and Fluorescein on goethite. These results indicate a higher chemical affinity of Alizarin by the goethite surface. Alizarin on magnetite shows a similar $\mathrm{pH}$ behavior but with lower adsorbed amount. The differences between goethite and magnetite BET area can partially justify these results.

Although several reviews on the topic of decolorisation focus on microbiological/enzymatic methods, the adsorption is still considered simple and economical in comparison. ${ }^{36,37}$ Guibal et al..$^{38}$ have shown the properties of chitosan related to Reactive Black dye, a structurally very complex azo dye with sulfonic groups. They showed that more than 7 moles of amino groups are needed for the sorption of $1 \mathrm{~mol}$ of dye. This greatly exceeds the stoichiometry required for the neutralization of charges of sulfonic groups. All the amino groups are not really active/ available or at least accessible to the dyes. The weakly porous structure of the polymer and its residual crystalline are also critical parameters for the hydration and the accessibility to sorption sites. ${ }^{35}$ The interactions of 
the dye with different monomer units of the polymer lead to a kind of cross-linking effect that induces the gelation of the polymer chains and the insolubilization of this material with the formation of flocs.

The analysis of the adsorption parameters suggests that they are closely related to the nature of the species present in the solution. There is no correlation between BET area and Langmuir parameters, mainly because the problem is electrostatic in nature and related to polymer swelling in the case of chitosan - besides the hydrogen bonding (see Figure 1S in Supplementary Material). In this case, hydrogen bonding, electrostatic interactions and hydrophobic interactions can be important to explain the uptake (including chitosan swelling and structural changes in the boundaries of chitosan chains H-bonding because of dyes coordination). In the case of the oxides, the surface chemistry is totally different and hydrophobic forces only could be acting at solution, in terms of aggregation of the dyes to form dimmers or other higher level aggregates ${ }^{30}$ Chitosan was used in the solid form to compare its effects with the iron oxides. However, a high amount of active sites remain unavailable to the dye when chitosan is in the solid state. ${ }^{38}$ For dye solutions, results showed that solution color can be removed either by sorption onto solid state chitosan or by coagulation-flocculation using dissolved state chitosan.

For this "solid" chitosan, diffusion controlled mechanisms have been considered as adequate for dye adsorption modeling. The monovalent and smaller dyes are reported to be more adsorbed than bigger and multivalent ones because of the ability to get widespread attachment to $\mathrm{NH}_{2}$ active adsorption sites. ${ }^{31,35,38}$ This is in line with our results. Comparing Figure 1S (Supplementary Material) and Figure 3 a best comprehension about the different adsorption mechanisms between chitosan and an iron oxide can be achieved.
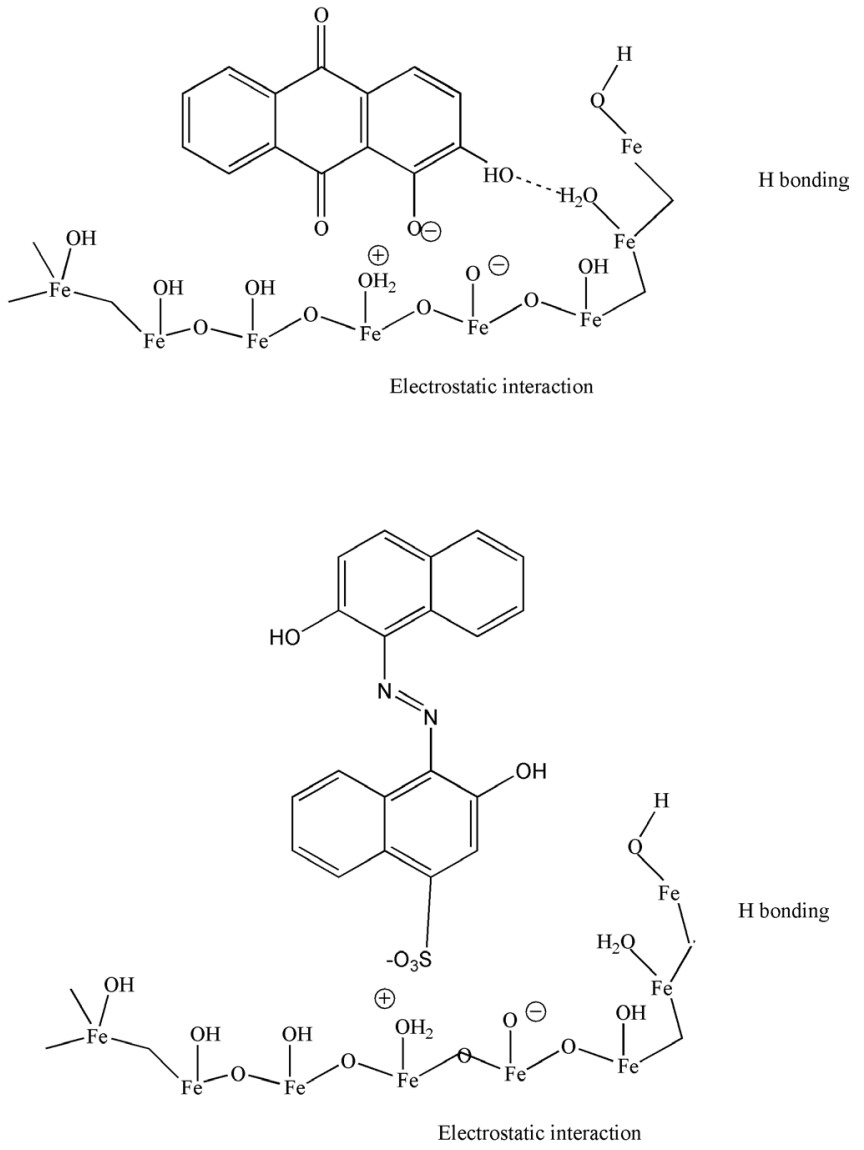

Figure 3. Interactions of Alizarin and Eriochrome Blue Black R adsorption on iron oxides
The neutral $\mathrm{pH}$ demonstrated to be the best for chitosan, because of surface charge considerations and the analysis of the polycationic nature of chitosan, whereas acidic $\mathrm{pH}$ was the best for the iron oxides to reach the maximum uptake. The behavior of chitosan shown here - with a maximum at pH 7 for Alizarin and Eriochrome Blue Black R - has been seen in $\mathrm{Cr}$ adsorption on chitosan..$^{39}$ Partial agglomerations at $\mathrm{pH} 5$ because of protonation - and therefore unavailability of active adsorption sites - and intramolecular bonding and electrostatic repulsion at $\mathrm{pH} 9$ where the absence of protanated amino groups in alkaline media restrains the interaction of chitosan with the negative charges of the dye can explain this apparently anomalous behavior with $\mathrm{pH}$ when Alizarin and Eriochrome Blue Black R adsorption are analyzed. ${ }^{40}$

Chitosan does not adsorb Fluorescein in appreciable amounts. In solution, Fluorescein dimerizes through $\mathrm{H}$-bonding in protic solvents. ${ }^{41}$ The existence of trimers and further aggregates has been also reported for this dye. ${ }^{42}$ The dimerization enthalpy and entropy for Fluorescein are -7.6 and $-21.7 \mathrm{cal} / \mathrm{mol} \mathrm{K}$. On the basis of these values, the association is mediated by hydrogen bonding with the water molecules. Molecular Dynamics simulations and 1-D and 2-D NMR experiments have been performed to study the dimerization process of xanthene dyes on the surface of oxides. ${ }^{43,44}$ Dimmers can adopt two different structures: parallel and antiparallel, not distinguible by photometric methods at solution. The structures of the Fluorescein dye have been studied and two main forms are proposed to take place on certain metallic surfaces. They are: 1) the molecules are paired on the surface through the $\mathrm{OH}---\mathrm{OH}$, or 2) the molecules are paired through the $\mathrm{C}=\mathrm{O}$ and the $\mathrm{OH}$. The configuration 2) has higher van der Waals forces and hydrogen bonding. ${ }^{45}$

With these ideas in mind, we propose that chitosan (a polycation biopolymer) promotes aggregation of the dyes making them unavailable to adsorption of the $\mathrm{NH}_{3}{ }^{+}$sites of the chitosan whereas the interaction with the iron oxides surfaces disaggregates the dyes agglomeration, rendering them monomeric and available to adsorption on the goethite and magnetite surface.

The kind of structure of Fluorescein makes the availability of the carboxylate group very difficult for adsorption. Because of the loss of the symmetry that takes place when the Fluorescein forms the monoanion, the ring with the $\mathrm{OH}$ attached is fully aromatic whereas the other is a quinone. As a result the benzoate moiety has a $70^{\circ}$ dihedral angle with respect to the xanthene moiety leaning towards the phenolic ring. ${ }^{17}$ Figure $2 \mathrm{~S}$ (Supplementary Material) shows the steric hindrance to adsorption in the case of Fluorescein, especially when a polycationic structure such as chitosan is present, with a particular orientation of the $\mathrm{NH}_{3}{ }^{+}$moiety. In the case of the iron oxides, the interaction can be more effective sterically because of the surface structure.

From the data, clearly the BET area of the adsorbents has not relation with the ability to adsorb the selected dyes on chitosan/iron oxides, because the BET area of chitosan is an order of magnitude lower than the iron oxides. The electrostatic nature of the interaction and the steric hindrance plus the effect of the double layer near the oxide, the $\mathrm{pH}$, the surface ionic structure and the van der Waals interactions are of paramount importance.

\section{CONCLUSIONS}

From the kinetics experiences a fast adsorption of all dyes on both chitosan and iron oxides could be verified. In all cases the equilibrium is reached within of the first sixty minutes. Chitosan and the iron oxides studied are interesting as dyes adsorbents. In all cases the chitosan was an excellent adsorbent (better than the iron oxides) for Alizarin and Eriochrome Blue Black R. Among the iron oxides, goethite is the most effective adsorbent. In the case of Fluorescein, goethite at $\mathrm{pH}$ 
5 and 9 was more effective as adsorbent than chitosan. Comparing chitosan with goethite and magnetite at $\mathrm{pH} 7$ can be observed one or two orders of magnitude lower for Alizarin adsorption (0.274 to $1.54 \mathrm{mmol}$ dye/g adsorbent) and two order of magnitude lower (3.66 $10^{-2}$ to $6.6310^{-2} \mathrm{mmol}$ dye/g adsorbent) for Eriochrome Blue Black $\mathrm{R}$. The iron oxides present a closely relation between their behavior and the surface structure, the BET surface area can be considered as a parameter useful to compare their adsorption capacity. On the other hand, the adsorption capacity of chitosan depends on the available amino groups present in its structure, in this way a clear correlation of the adsorption capacity with the $\mathrm{pH}$ is found.

\section{SUPPLEMENTARY MATERIAL}

Scheme 1S, Figures $1 \mathrm{~S}$ and $2 \mathrm{~S}$. This material is available at http:// www.quimicanova.sbq.org.br, in PDF file.

\section{ACKNOWLEDGEMENTS}

M. L. Ferreira and S. Pirillo acknowledge CONICET for the financial support. The authors acknowledge financial support from Universidad Nacional del Sur (Bahía Blanca, Argentina).

\section{REFERENCES}

1. Robinson, T.; McMullan, G.; Marchant, R.; Nigam, P.; Bioresour. Technol. 2001, 77, 247.

2. Kothuis, B.; Schelleman, F.; Discussion paper for the Workshop on Biotechnology for Cleaner Production, Institute for Applied Environmental Economics: The Netherland, 1995.

3. Cooper, S. G.; The Textile Industry. Environmental Control and Energy Conservation, Noyes Data Corporation Press: New Jersey, 1978.

4. Yu-Li Yeh, R.; Thomas, A.; J. Chem. Technol. Biotechnol. 1995, 63, 55.

5. Guaratini, C. C. I.; Zanoni, M. V. B.; Quim. Nova 2000, 23, 71.

6. Kang, S. F.; Liao, C. H.; Po, S. T.; Chemosphere 2000, 41, 1287.

7. McKay, G.; Otterburn, M.; Aga, J.; Water, Air, Soil Pollut. 1987, 33, 419.

8. Kumar, M. N. V. R.; React. Funct. Polym. 2000, 46, 1.

9. Wu, F. C.; Tseng, R. L.; Juang, R. S.; J. Hazard. Mater. 2000, 73, 63.

10. Chiou, M. S.; Ho, P. Y.; Li, H. Y.; J. Chin. Inst. Chem. Eng. 2003, 34, 625.

11. Uzun, I.; Dyes Pigm. 2006, 70, 76.

12. Chiou, M. S.; Ho, P. Y.; Li, H. Y.; J. Chin. Inst. Chem. Eng. 2003, 34, 625.

13. Saffaj, N.; Persin, M.; Younssi, S. A.; Albizane, A.; Bouhria, M.; Loukili, H.; Dach, H.; Larbot, A.; Sep. Purif. Technol. 2005, 47, 36.

14. Cornell, R. M.; Schwertmann, U.; The Iron Oxides. Structure, Properties, Reaction, Occurrence and Uses, VCH: Weinheim, 1996.

15. Pirillo, S.; Ferreira, M. L.; Rueda, E. H.; Ind. Eng. Chem. Res. 2007, 46, 8255 .
16. Wu, Z.; Joo, H.; Ahn, I. S.; Haam, S.; Kim, J. H.; Lee, K.; Chem. Eng. J. 2004, 102, 277.

17. Wang, L.; Roitberg, A.; Meuse, C.; Gaigalas, A. K.; Spectrochim. Acta, Part A 2001, 57, 1781.

18. Atkinson, R. J.; Posner, A. M.; Quirk, J. P.; J. Inorg. Nucl. Chem. 1968, 30,2371 .

19. Regazoni, A. E.; Ph.D. Thesis, Comisión Nacional de Energía Atómica, Departamento Química de Reactores, Buenos Aires, Argentina, 1984.

20. Voudrias, E.; Fytianos, K.; Bozani, E.; Global Nest: the Int. J. 2002, 4, 75.

21. Karadag, D.; Dyes Pigm. 2007, 74, 659.

22. Önal, Y.; J. Hazard. Mater. 2006, 137, 1719.

23. Maximova, A.; Koumanova, B.; J. Univ. Chem. Technol. Metal. 2008 $43,101$.

24. Venkata Rao, B.; Sastry, C. A.; Indian J. Environ. Protect. 1987, 7, 363.

25. Harris, R. G.; Wells, J. D.; Angove, M. J.; Johnson, B. B.; Clays Clay Miner. 2006, 54, 456.

26. Mohan, D.; Singh, K. P.; Singh, G.; Kumar, K.; Ind. Eng. Chem. Res. 2002, 41, 3688.

27. Allen, S. J.; McKay, G.; Khader, K. Y. H.; J. Chem. Technol. Biotechnol. 1988, 45, 517.

28. Pendleton, P.; Wu, S. H.; J. Colloid Interface Sci. 2003, 266, 245.

29. Allen, D. J.; Koumanova, B.; J. Univ. Chem. Technol. Metal. 2005, 40, 175.

30. Chan, M. Y.; Juang, R. S.; Colloids Surf., A 2005, 269, 35.

31. Sakkayawong, N.; Thiravetyan, P.; Nakbanpote, W.; J. Colloid Interface Sci. 2005, 286, 36 .

32. Cestari, A. R.; Vieira, E. F. S.; dos Santos A. G. P.; Mota, J. A.; de Almeida, V. P.; J. Colloid Interface Sci. 2004, 280, 380.

33. Chiou, M. S.; Ho, P. Y.; Li, H. Y.; Dyes Pigm. 2004, 60, 69.

34. Wong, Y. C.; Szeto, Y. S.; Cheung, W. H.; McKay, G.; Process Biochem. 2004, 39, 693.

35. Cheung, W. H.; Szeto, Y. S.; McKay, G.; Bioresour. Technol. 2007, 98, 2897.

36. Walker, G. M.; Weatherley, L. R.; Chem. Eng. J. 2001, 83, 201.

37. Forgacs, E.; Cserháti, T.; Oros, G.; Environ. Int. 2004, 30, 953.

38. Guibal, E.; Touraud, E.; Roussy, J.; World J. Microbiol. Biotechnol. $\mathbf{2 0 0 5}, 21,913$.

39. Webster, A.; Halling, M. D.; Grant, D. M.; Carbohydr. Res. 2007, 342, 1189.

40. Rosa, S.; Laranjeira, M. C. M.; Riela, H. G.; Fávere, V. T.; J. Hazard. Mater. 2008, 155, 253.

41. Valdes-Aguilera, O.; Neckers, D. C.; Acc. Chem. Res. 1989, 22, 171.

42. López Arbeloa, I.; J. Chem. Soc. Faraday Trans. 2 1981, 77, 1725.

43. Pelet, S.; Grätzel, M.; Moser, J. E.; J. Phys. Chem. B 2003, 107, 3215.

44. Daré-Doyen, S.; Doizi, D.; Guilbaud, Ph.; Djedaïni-Pilard, F.; Perly, B.; Millié, Ph.; J. Phys. Chem. B 2003, 107, 13803.

45. Su, G. J.; Yin, S. X.; Wan, L. J.; Zhao, J. C.; Bai, C. L.; Surf. Sci. 2004, $551,204$. 


\section{ELIMINATION OF DYES FROM AQUEOUS SOLUTIONS USING IRON OXIDES AND CHITOSAN AS} ADSORBENTS. A COMPARATIVE STUDY

Silvina Pirillo*, Viviana Pedroni y Elsa Rueda

Departamento de Química, Universidad Nacional del Sur, CP 8000, Bahía Blanca, Argentina

María Luján Ferreira

Planta Piloto de Ingeniería Química, Universidad Nacional del Sur (UNS-CONICET), Camino La Carrindanga km 7, CC 717, CP 8000, Bahía Blanca, Argentina

(b)<smiles>O=C(O)c1ccccc1-c1c2ccc(=O)cc-2oc2cc(O)ccc12</smiles>

Scheme 1S. Chemical structures of the dyes used. a) Alizarin, b) Eriochrome Blue Black R, and c) Fluorescein 


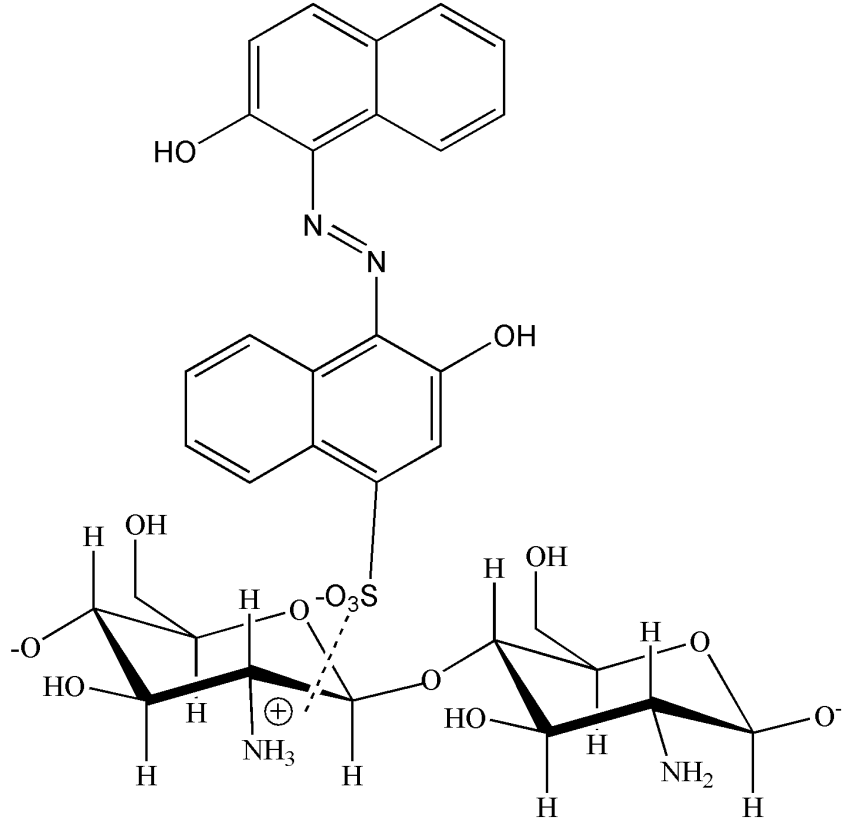

Electrostatic interaction

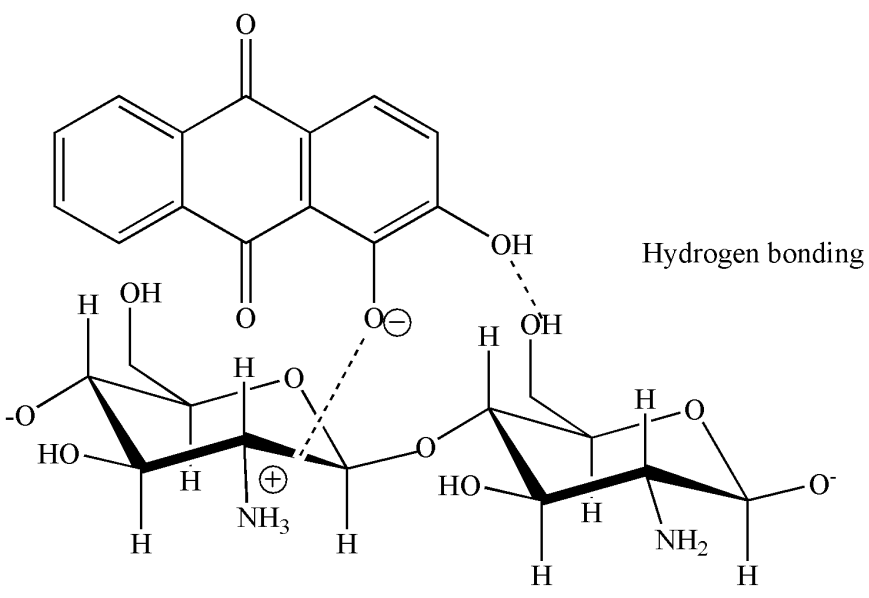

Figure 1S. Interactions of Alizarin and Eriochrome Blue Black R adsorption on chitosan 


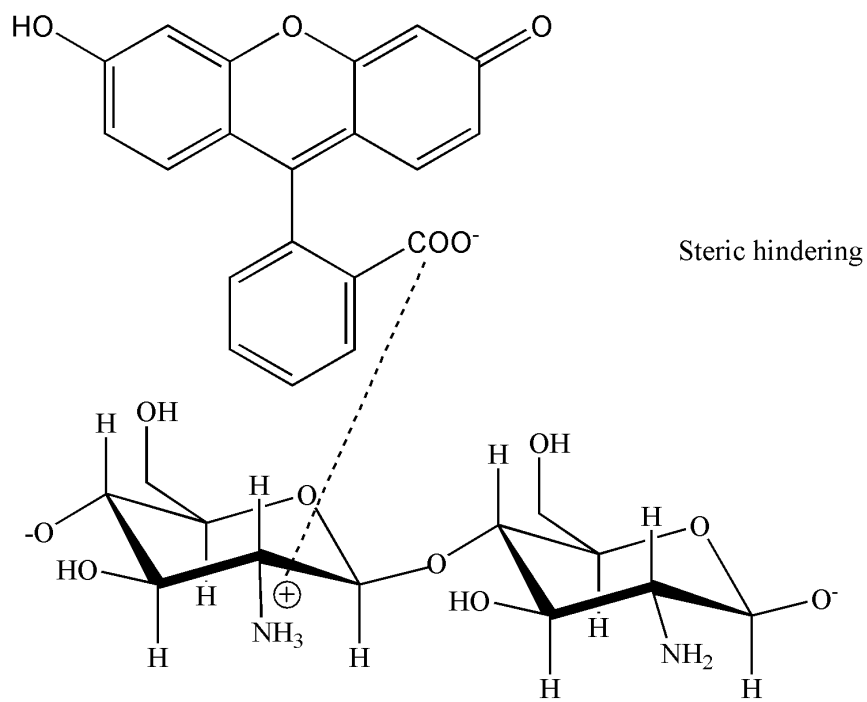

Electrostatic interaction

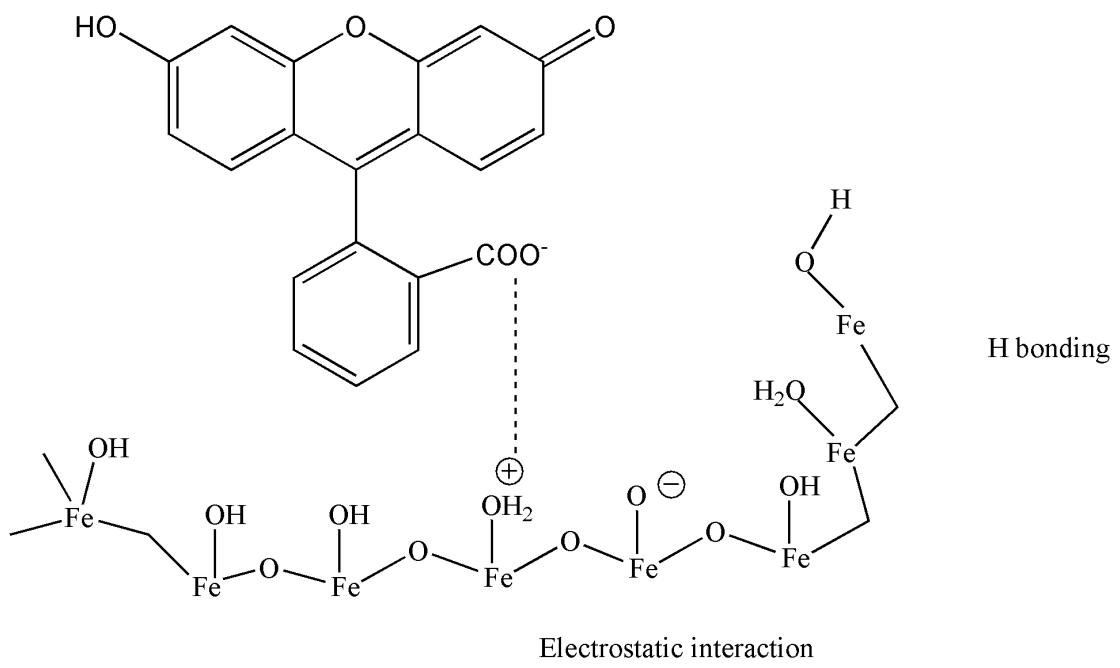

Figure 2S. Interactions and steric hindrance of the adsorption of Fluorescein on chitosan and iron oxides 